\title{
EVALUATION OF VETERINARY PHARMACEUTICAL AND IODINE FOR USE AS A GROUNDWATER TRACER IN HYDROLOGIC INVESTIGATION OF CONTAMINATION RELATED TO DAIRY CATTLE OPERATIONS
}

Larry "Boot" Pierce

Missouri Geological Survey, 111 Fairgrounds Road. Rolla, MO 65401, USA, larry.pierce@dnr.mo.gov

Honglin Shi

Missouri University of Science and Technology, 1870 Miner Circle, Rolla, MO 65409,USA, honglin@mst.edu

\begin{abstract}
Standard groundwater tracers such as Rhodamine WT, Fluorescein, Eosin and Tinopal CBX effectively provide a snapshot of hydrological conditions over a brief period of time and in a tightly controlled setting. However, in complex environmental situations with multiple potential sources, groundwater hydrologists are often seeking groundwater tracers that have extended longevity in the natural environment and the ability to directly pinpoint source locations. After reviewing operations of the nearby dairy it was determined that emerging contaminants, specifically two bovine veterinary pharmaceuticals (antibiotics), cephapirin sodium (CEPNa) and cephapirin benzathine (CEPB), and a sanitation agent, elemental Iodine (I) may have potential as extended longevity groundwater tracers if analytical methodology could be established. Initially, sample analysis indicated that cephapirin is undetectable in unconcentrated samples of lagoon wastewater at parts per billion (ppb) concentration; pre-concentrated samples which utilized solid phase extraction allowed for better detection at part per trillion level. Concentrated samples from one of the two lagoon cells sampled (cell \#3), detected cephapirin at 13.14 ppt level, while cell \#1 failed to detect any cephapirin present. Controlled laboratory testing later indicated that in a wastewater environment cephapirin degrades to approximately $20 \%$ of initial concentrations within 4 days, with complete degradation within 6 days. Degradation patterns in surface water and groundwater samples were less dramatic and at slower rates. Degradation curves of the surface and groundwater samples indicate that concentrations of cephapirin are still detectable for approximately 25 days. Unconcentrated Iodine samples collected in lagoon cells ranged from $50.896 \mathrm{ppb}$ and $1,704.55 \mathrm{ppb}$ with variations determined to be a result of the primary inflow of the lagoon. Cephapirin's use as
\end{abstract}

a long term groundwater tracer does not seem to be an immediate option. Further research may reveal that its degradation products are potentially useful as a tracer. In some instances, such as catastrophic discharges of large volumes of milk when samples can be collected and analyzed quickly, the use of cephapirin as an environmental tracer may prove possible. The validity of pharmaceutical iodine as a groundwater tracer appears to be much greater than that of cephapirin. Iodine was detected in all of the environmental samples including the highly organic and anaerobic environment of the dairy wastewater lagoon. This study concludes that iodine is capable of surviving the hostile wastewater environment. If sufficient data is collected to determine natural background levels, iodine may prove useful in determining hydrological connections between iodine laden dairy effluent and the underlying groundwater.

\section{Introduction}

Investigation of the hydrologic environment in the vicinity of a fitness center in Southeast Missouri began in the summer of 2010. This investigation included a series of water traces utilizing the standard fluorescent dyes such as fluorescein and Rhodamine WT to evaluate potential sources of bacteria entering the center's well. The sources included surface water infiltration surrounding the wellhead, onsite septic system failures and a nearby dairy operation (Pierce, 2012).

After reviewing operations of the nearby dairy it was determined that additional groundwater tracers may be present in the form of veterinary pharmaceuticals and sanitizing agents. A two-fold investigation was then initiated. The first phase of the investigation was to determine if these pharmaceuticals/sanitizing agents were detectable in a laboratory environment. Once the analysis methodology was proven to be successful, 
the potential for their survival in natural environments or highly organic and anaerobic conditions of dairy wastewater lagoons needed to be determined. The second phase was to then test the applicability of the pharmaceuticals and sanitizing agents as long term groundwater tracers in the natural environment.

\section{Background}

Literature reviews and research revealed that the potential for water tracing using emerging contaminants such as bovine pharmaceutical compounds, trace elements and other chemicals used in sterilization and milking process may be possible (Boxall et al., 2003; Drewes et al., 2003; Jones, 2009).

Emerging contaminants, specifically two bovine veterinary pharmaceuticals (antibiotics), cephapirin sodium (CEPNa) and cephapirin benzathine (CEPB), and a sanitation agent, elemental Iodine (I) are detectable in groundwater samples (Santschi, et al; 1999) and have potential for use as long-term groundwater tracers for hydrogeologic investigations where dairy operations are a potential source of contaminant (Boxall et al., 2003; Drewes et al. 2003; Jones, 2009).

Through the course of several conversations the State of Missouri's dairy inspector indicated that the pharmaceutical products cephapirin sodium (CEPNa) and cephapirin benzathine (CEPB were routinely used for treatment of dairy cows at the nearby dairy operation. According to literature the vast majority of cephapirin is excreted unchanged in the urine. Most excretion occurs within 8 hours of application and the process of excretion completed within 72 hours (Jones, 2009). Additionally, the inspector indicated that iodine is used as a sterilization agent for the cleaning of teats both before and after milking at the dairy operation. It too is washed to the lagoon and thus has the potential to reach the natural environment in a similar manner to the cephapirin.

Further literature research indicated that some pharmaceuticals and iodine are detectable in groundwater samples. (Santschi et al., 1999) Therefore, if analyzable and detectable in environmental samples, CEPNa, CEPB, and iodine may potentially be used as tracers to investigate the groundwater hydrology of the CAFFC area to determine whether the contamination in the affected well is related to the dairy operations.
If a hydrologic connection between the CAFFC well and the nearby dairy operation exist then testing should reveal cephapirin, used in the dairy operation, to be present in CAFFC water samples. Additionally, iodine levels should be elevated in water samples when compared to natural background iodine concentrations.

To determine if Cephapirin was readily detectable Dr. Honglan Shi at Missouri University of Science and Technology was contracted to develop liquid chromatography-tandem mass spectrometry (LC-MS/ MS) methods to analyze water samples for the bovine antibiotic. In addition Dr. Shi developed protocol for inductively coupled plasma mass spectrometry (ICPMS) to analyze for total iodine concentrations. Upon completion, the methodological process was put into service to analyze for these constituents in the field samples associated with the CAFFC well investigation.

\section{Cephapirin and lodine Analysis Development}

The results of the cephapirin analysis methodology development were mixed. Dr. Shi was able to successfully develop a reliable, fast and simple method for detecting the base Cephapirin (CEP) molecule in water samples to the part per trillion (ppt) level. However difficulties were also observed in the analysis of field samples, stability studies showed that the Cephapirin degrades to form a degradant (DACEP) in all sample matrices (water and lagoon effluent). In a series of further test conducted on spiked samples the degradation was shown to be highest in the lagoon samples with complete degradation of CEP to DACEP within six days when left at room temperature. Figure 1 highlights these degradation rates. Analysis of samples in both groundwater and surface water matrices also show similar degradation patterns, but at a slower rate. Testing revealed that the currently analyzable degradants was also unstable and quickly degraded to undetectable levels.

The ICP-MS analysis methodology for total iodine in water samples was previously developed by Dr. Shi and the MS\&T laboratory in 2009 and would be used for the investigation (Shi and Adams, 2009).

\section{Field Sampling and Investigation}

As part of the initial dye tracing, a well survey was conducted by MGS to locate and inventory any groundwater wells servicing residence, farms, or 


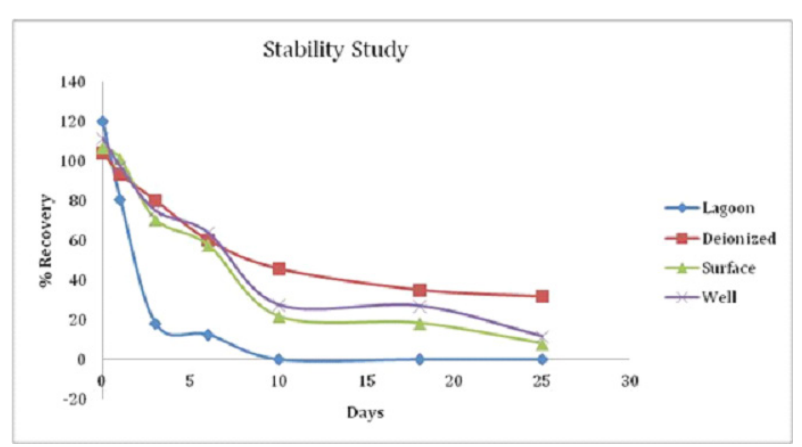

Figure 1. Cephapirin degradation patterns by matrix.

businesses in the vicinity of the CAFFC. This survey was expanded to additional locations to help establish a more representative natural Iodine background for the area.

Following the survey, wells in the vicinity of the CAFFC site were sampled and analyzed for the presence of cephapirin and iodine. Wastewater samples were collected from each cell of dairy's two-cell wastewater lagoons. A representative population of inventoried wells was selected for sampling and analysis to establish natural background levels of iodine. As well as a small nearby spring and surface water samples from Williams Creek and the small tributary below the dairy operation. A total of nineteen water samples were initially collected for analysis. Two additional samples were collected at a later date to allow for the SPE and pre-concentration analysis. Figure 2 is a map showing all sample locations.

Samples were collected using procedures to meet MDNR standards and the methodology needs for Dr. Shi's analysis. Water samples were collected in pre-cleaned, 4-ounce, Teflon- capped, wide-mouth amber bottles. For well water collection at homes, the faucet aerator was first removed (if present) and the water allowed to flow for approximately 5 minutes. Sample bottles were then filled. Surface water sample bottles were submersed and filled directly in the sampling bottle. For wastewater

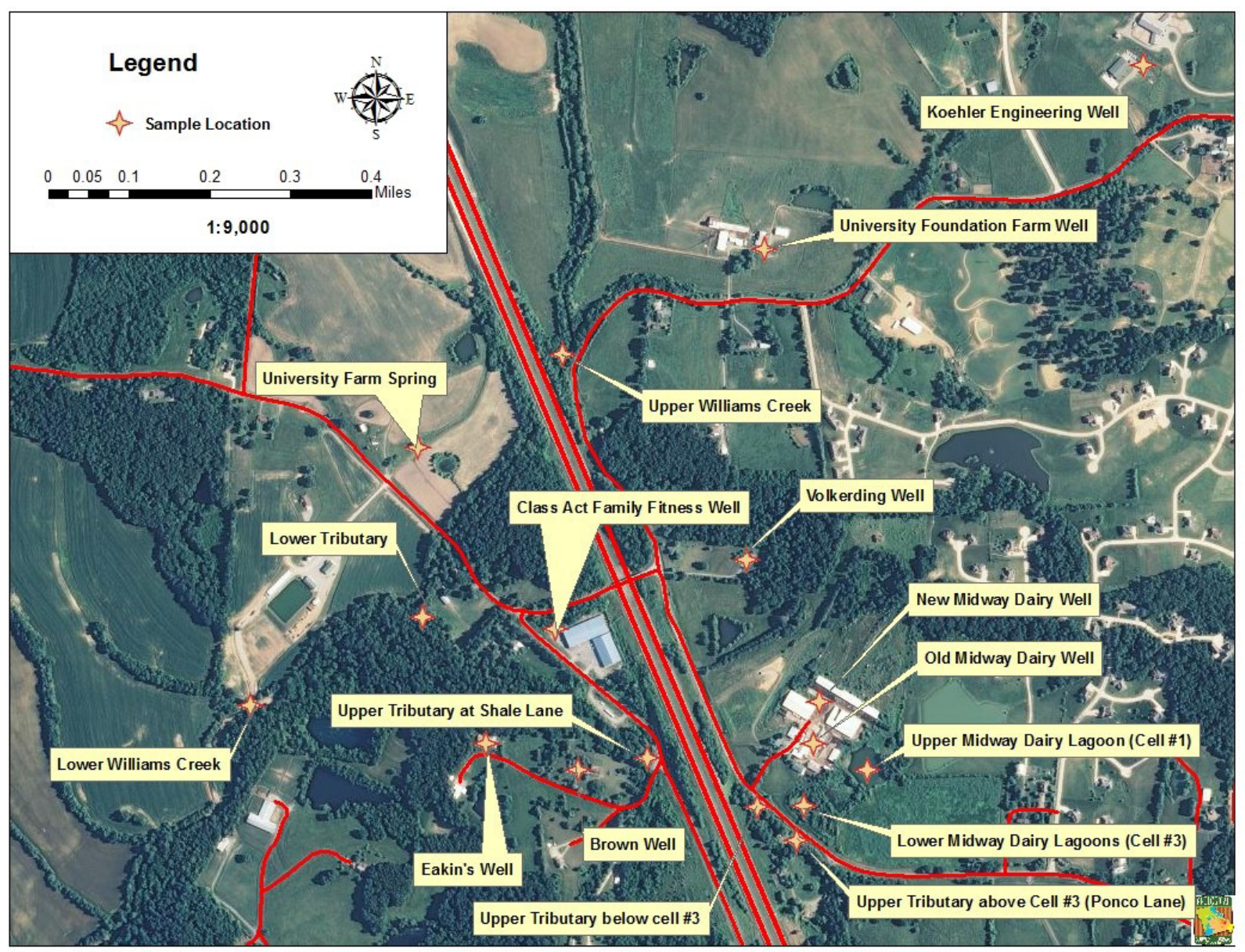

Figure 2. Sample location map. 
samples a reusable sample dipper was utilized and subsequently cleaned and decontaminated between uses to avoid cross-contamination. Field blanks, trip blanks, and duplicate samples were collected throughout the sampling event as a quality assurance measure. The collected samples were sealed and placed in an iced cooler then transferred to the University of Missouri Science and Technology laboratory using standard MDNR chain of custody protocol.

\section{Results}

Analysis of collected samples initially indicated no detection of cephapirin in the wastewater lagoons at part per billion (ppb) levels. A second round of sampling was conducted on the wastewater lagoons. At this time larger volumes of sample were collected so that a solid phase extraction (SPE) could be used to pre-concentrate the cephapirin and allow for better detection sensitivity to the PPT level. In this analysis large volumes of lagoon waste were reduced to approximately $10 \%$ of its original amount while still retaining the concentrations of cephapirin. In this second analysis a two liter sample taken from the taken from cell \#3 of the dairy lagoon treatment system, detected 13.14 ppt of Cephapirin. Analysis of a sample from cell \#1 failed to detect any cephapirin.

Iodine levels collected from the study area ranged from $4.939 \mathrm{ppb}$ to $1704.55 \mathrm{ppb}$ and are shown in Table 1. Iodine was detected in all eight drinking water wells with concentrations ranging from 4.939 to $24.712 \mathrm{ppb}$ with a mean concentration of $12.532 \mathrm{ppb}$ and a standard deviation of $6.672 \mathrm{ppb}$. Six surface water samples were collected and analyzed with concentrations ranging from 6.671 to $21.247 \mathrm{ppb}$. The mean concentration of iodine in surface water samples was $14.732 \mathrm{ppb}$ with a standard deviation of $5.489 \mathrm{ppb}$. A single sample from a shallow spring was collected and determined to have $5.855 \mathrm{ppb}$ iodine present.

Samples collected and analyzed from lagoon cell \#1 and lagoon cell \#3 contained 50.896 ppb and 1,704.55 ppb iodine, respectively. A considerable difference in iodine concentrations is obvious in the lagoon samples. Further investigation revealed that the lagoons are not successive and that the source area and influents of waste were different for each. The primary waste source for lagoon cell \#1 is runoff from the animal feed lot and loafing areas. Lagoon cell \#3 received some barnyard runoff similar to cell \#1. However, the influent of wash water from the milking parlor was also observed discharging into the cell. Since iodine is used to sanitize teats prior to milking its presence in the daily cleaning effluent is not uncommon and likely explains the large difference in iodine concentration between cell \#1 and cell \#3.

\section{Conclusion}

Due to the instability of cephapirin its use as a long term groundwater tracer does not seem to be an immediate option. Future research may at some point identify a specific cephapirin degradant product that has the stability and environmental longevity required for groundwater tracing, but at this time those degradants have yet to be identified. In some instances such as direct runoff, catastrophic lagoon failures or discharges of large volumes of milk, where samples can be collected and analyzed in a rather quick time frame, the use of cephapirin or its degradants as an environmental tracer may prove possible.

Table 1. Sample locations and iodine concentrations.

\begin{tabular}{|c|c|c|}
\hline Sample ID & Sample Name & Concentration PPB \\
\hline FB001 & Field Blank & $<0.2$ \\
\hline TB001 & Trip Blank & $<0.2$ \\
\hline WW001 & $\begin{array}{l}\text { Class Act Family Fitness } \\
\text { Center }\end{array}$ & 16.178 \\
\hline WW002 & Koehler Engineering Well & 11.472 \\
\hline WW003 & University Farm Well & 11.93 \\
\hline WW004 & Volkerding Well & 4.939 \\
\hline WW005 & New Midway Dairy Well & 24.712 \\
\hline WW006 & Old Midway Dairy Well & 6.255 \\
\hline WW007 & Dave Brown Well & 19.31 \\
\hline WW008 & Wayne Eakins Well & 5.457 \\
\hline SS001 & Upper Williams Creek & 6.671 \\
\hline SS002 & Lower Williams Creek & 9.216 \\
\hline SS003 & Tributary at Shale Lane & 21.247 \\
\hline SS004 & $\begin{array}{l}\text { Tributary just above } \\
\text { confluence with Williams } \\
\text { Creek }\end{array}$ & 20.23 \\
\hline SS005 & $\begin{array}{l}\text { Tributary just below } \\
\text { outfall of dairy lagoon } \# 3\end{array}$ & 13.117 \\
\hline SS006 & $\begin{array}{l}\text { Tributary above dairy } \\
\text { lagoon outfall (Ponco } \\
\text { Lane) }\end{array}$ & 17.913 \\
\hline SP001 & Spring on University Farm & 5.855 \\
\hline LG001 & Lagoon Cell \#1 & 50.896 \\
\hline LG002 & Lagoon Cell \#3 & 1704.55 \\
\hline
\end{tabular}


The validity of iodine as an extended-longevity groundwater tracer appears to be much higher than the cephapirin. Iodine was detected in all of the environmental samples including the highly organic and anaerobic environment of the dairy wastewater lagoon. Iodine levels within dairy lagoons \#1 and \#3 were found to be $206 \%$ to $6898 \%$ higher than background samples. This study concludes that iodine is capable of surviving a hostile wastewater environment. If sufficient data is collected to determine natural background levels, the use of iodine may prove useful in determining hydrological connections between iodine laden dairy effluent and the underlying groundwater.

\section{References}

Boxall, ABA, Kolpin DW, Halling-Sørensen B, Tolls J. 2003. Are Veterinary Medicines Causing Environmental Risks? Environmental Science and Technology. 37 (15): 286A-294A.

Drewes JE, Heberer T, Rauch T, Reddersen K. 2003. Fate of Pharmaceuticals During Ground Water Recharge. Ground Water Monitoring \& Remediation. 23: 64-72.

Jones GM. 2009. On-farm Test for Drug Residuals in Milk. Virginia Cooperative Extension Publication number 404-401. Virginia Polytechnic Institute and State University: [cited 2015 Jul 20]. 5 p. Available online at: https://pubs.ext. vt.edu/404/404-401/404-401.html.

Pierce LD. 2012. Report on the Methodological Development and Analysis of Veterinary Pharmaceutical and Iodine for use as a Tracer in an Investigation of Groundwater Contamination Related to a Dairy Cattle Operation in Southeast Missouri. Missouri Geological Survey.

Santschi PH, Moran JE, Oktay S, Hoehn E. 1999. 129Iodine: A new tracer for surface water/ groundwater interaction. Isotope techniques in water resources development and management Proceedings, (Austria): 10-14 May. International Atomic Energy Agency (IAEA), Vienna. Available on CD-ROM.

Shi H, Adams C. 2009. Rapid IC-ICP/MS method for simultaneous analysis of iodoacetic acids, bromoacetic acids, bromate, and other related halogenated compounds in water: Talanta. 79: 523-527. 
